\section{A NEW TECHNIC FOR PERFORMING PERINEAL PROSTATECTOMY *}

\section{ARTHLR B. CECIL, M.D.} LOS ANGELES

It has for some time been my conviction that if Young's operation could be altered in such a manner as to rid it of technical difficulties, the procedure would lend itself to more general use. I therefore turned my attention toward the development of a technic which, it seemed to me, would rid perineal prostatectomy of any considerable technical difficulties and which would absolutely insure the integrity of the muscles of urinary control and at the same time protect the rectum from injury.

In reviewing the technic of Young's procedure in relation to the anatomy of the perineum, it will be seen that it is necessary to make very accurate entrance to the membranous urethra just back of the external sphincter muscle. To the operator who is not thoroughly familiar with the anatomy of the perineum, this is somewhat difficult or at least uncertain, and my first problem therefore seemed to be to alter this part of the procedure in such a manner that it would not be necessary to introduce a tractor through the membranous urethra, or to drain the bladder from this region. The result was the devising of a tractor which could be easily introduced through the entire length of the urethra, and which when opened in the bladder would be efficient in bringing the prostate into the wound, thus avoiding any possibility of injuring the

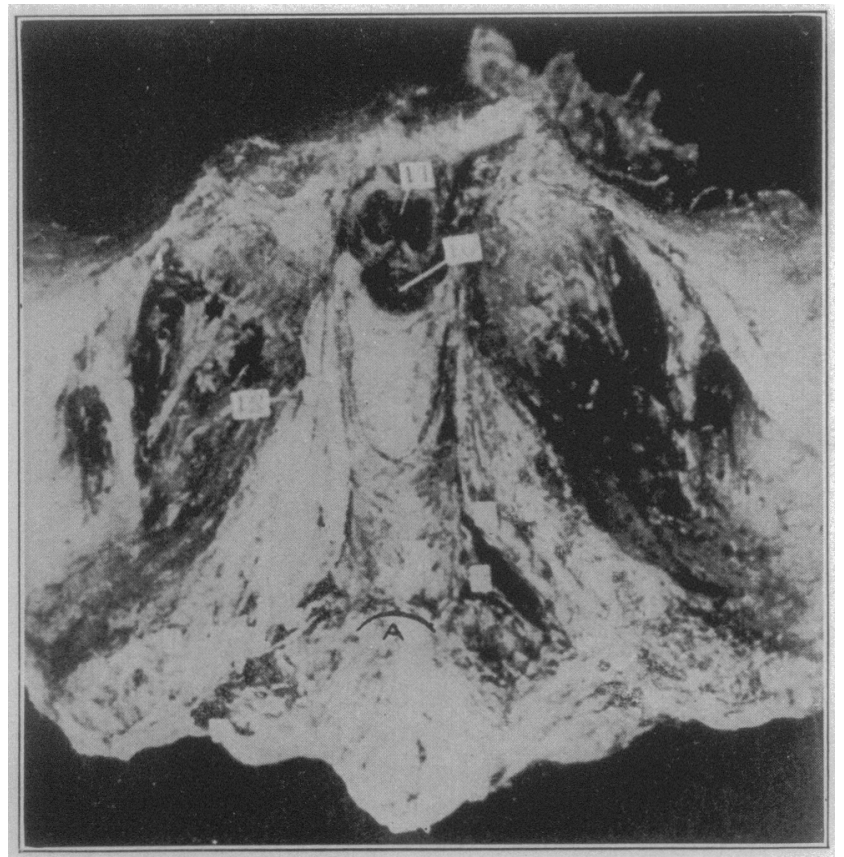

Fig. 1.-Anatomic dissection of perineum: $A$, point at which incision should be made across recto-urethralis muscle.

external sphincter muscle, and avoiding unnecessary scar formation in the region of this muscle.

The tractor which has been devised consists of a long shaft with a curved end, quite similar to the ordinary urethral sound. It has been so arranged that by turning a thumb screw at one end, the other end of the

* Read hefore the Section on Urology at the Seventy.Third Annual Session of the American Medical Assaciation, St. Louis, May, 1922. tractor is thrown at right angles. This rotation is brought about by a stout wire which runs through the shaft of the tractor. A handle has been arranged on the tractor, set at such an angle that by lifting up on the handle, the bladder end of the tractor produces traction on the prostate along practically the same plane as is generally brought about when Young's tractor is introduced through the membranous urethra. There

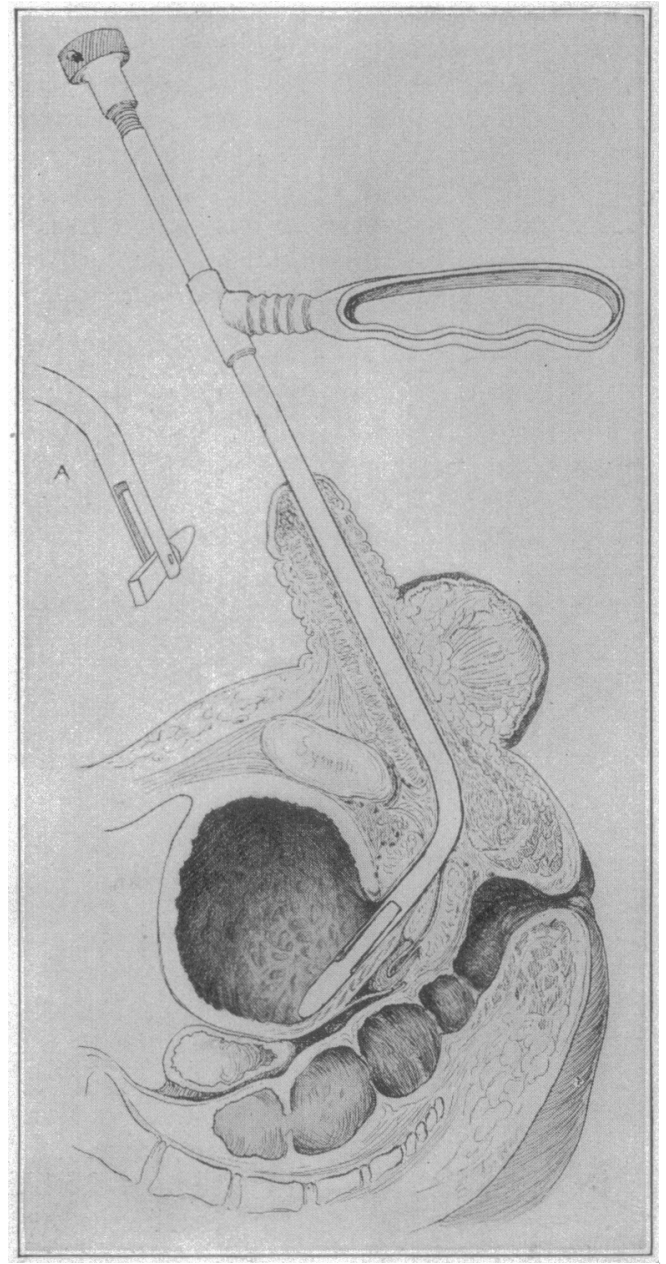

Fig. 2.-Incision through skin and subcutaneous tissues, with tractor introduced and being used as a sound.

may be slight variations in this relationship, according to the size of the prostatic tumor. By turning the thumb screw in the opposite direction, the right angle piece may again be brought into line with the tractor. A tractor devised much after the nature of this one, except for being straight instead of curved as a sound, has been found extremely efficient when the operation is performed by the technic of Young, as this type of tractor has the advantage of being easily introduced.

This modification of Young's technic having been arranged in order that the external sphincter mechanism might be easily preserved from injury, the only remaining difficulty would seem to be the uncertainty in dividing the recto-urethralis muscle. This difficulty has been met by changing the shaft of the handle of Young's bifid and spatula retractors, so that while these retractors may be firmly held in position, at the same time the operator may have the advantage of placing a gloved finger in the rectum to the apex of the prostate, and thus the dissection may be carried out 
under the sense of touch rather than by purely anatomic landmarks. As a matter of fact, if the operation is carried out by the sense of touch, anatomic landmarks will be followed.

The method of performing prostatectomy by this technic, then, consists in placing the patient on the table in the exaggerated lithotomy position, with the bladder partially filled with fluid, which permits the

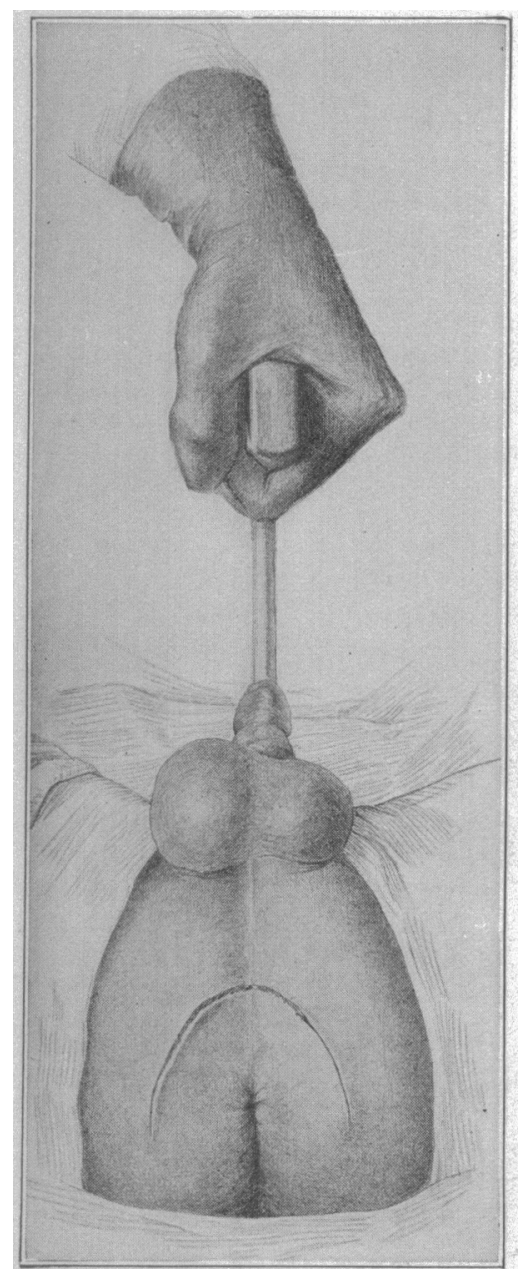

Fig. 3.-Sagittal section: tractor in place; $A$, bladder end of tractor after it has been

\section{easy opening of the} tractor. The curved tractor is passed into the bladder, and the V-shaped incision made in the perineum. In this connection one should note that the limbs of the curved $V$-shaped incision extend quite $\mathrm{far}$ back, and in making the incision it should be carried definitely through $t$ he subcutaneous $t$ issues rather boldly. The finger is then passed down into the fossa in front of the fibers of the levator ani muscle. The bifid retractor is now put in.

With a pair of thumb forceps, the tissues are picked up just back of the bulb, and the central tendon is divided $\mathrm{straight}$ downward. With the set-off bifid retractor now held firmly in place, a gloved finger is introduced into the rectum, and by means of a specially devised delicately curved clamp, the entire bridge of tissue down to the apex of the prostate is grasped under the direction of the guiding finger in the rectum. The tissues are now cut across above the clamp with definite assurance that no injury to the rectum is occurring, and in this manner the fibers of the recto-urethralis muscle are divided far back rather toward the rectal wall than toward the region of the external sphincter. The handle and shaft of the tractor are now brought toward the operator, thus throwing its bladder end freely into the bladder cavity so that the tractor may be easily opened, and by turning the thumb screw the bladder end of the tractor is thrown at right angles to the shaft. By now lifting on the tractor and pushing it away from the operator, the apex of the prostate is brought quite far up into the wound. The fibers of the levator ani muscle are pushed aside and the rectum is stripped back along the fascia of Denonvillier.

Up to this point no opening has been made into any portion of the urethra. The usual lateral incisions of
Young are made, as these have been found preferable to throwing back a large bridge of tissue. Adenomatous masses are freed by a blunt dissector, and removed through each lateral cavity by the technic described by Young. Having removed the masses from the lateral cavities and any suburethral lobes which may be encountered, an incision $2 \mathrm{~cm}$. in length is made through the right lateral cavity, and the edges of the prostatic urethra are picked up with Allison forceps. In some instances this is not necessary, because the prostatic urethra may be torn in removing the lateral lobes.

The edges of the prostatic urethra having been picked up, the tractor is removed, and in difficult cases it may be found advisable to introduce the straight tractor through this opening. A finger is passed in through the prostatic urethra, and the neck of the bladder palpated. Should an intravesical lobe be encountered, it is removed through this opening. Should the neck of the bladder be found contracted, it may be easily divided. After removal of all obstructing tissue, a single way drainage tube is introduced through this lateral cavity into the bladder and packed about with cephalin gauze to control hemorrhage.

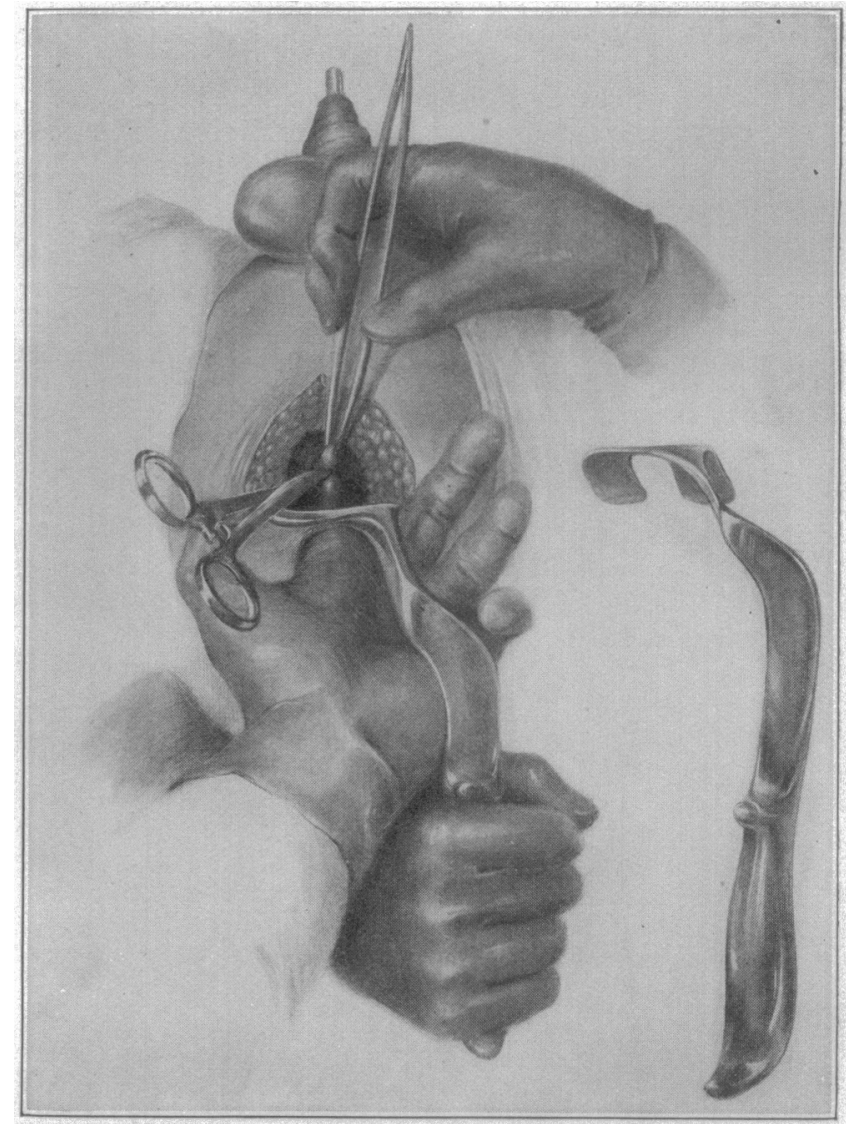

Fig. 4.-Posterior bifid retractor set off. Retractor has been introduced into the fossae between the transversus perineae muscles and the levator ani.

The closure of the wound in no manner differs from Young's original technic, and the postoperative care of the patient is so well known as to require no repetition here.

\section{CONCLUSION}

The technic which I have described has as its advantages definite preservation of the external sphincter muscle; the ability to carry out the perineal dissection 
with a guiding finger in the rectum; location of the opening for drainage far back in the prostatic urethra, which tends toward more rapid healing, and the absence of scar formation in the region of the external sphincter muscle.

It is believed that this technic will make it possible for surgeons to perform Young's perineal prostatectomy more easily than has heretofore been the case.

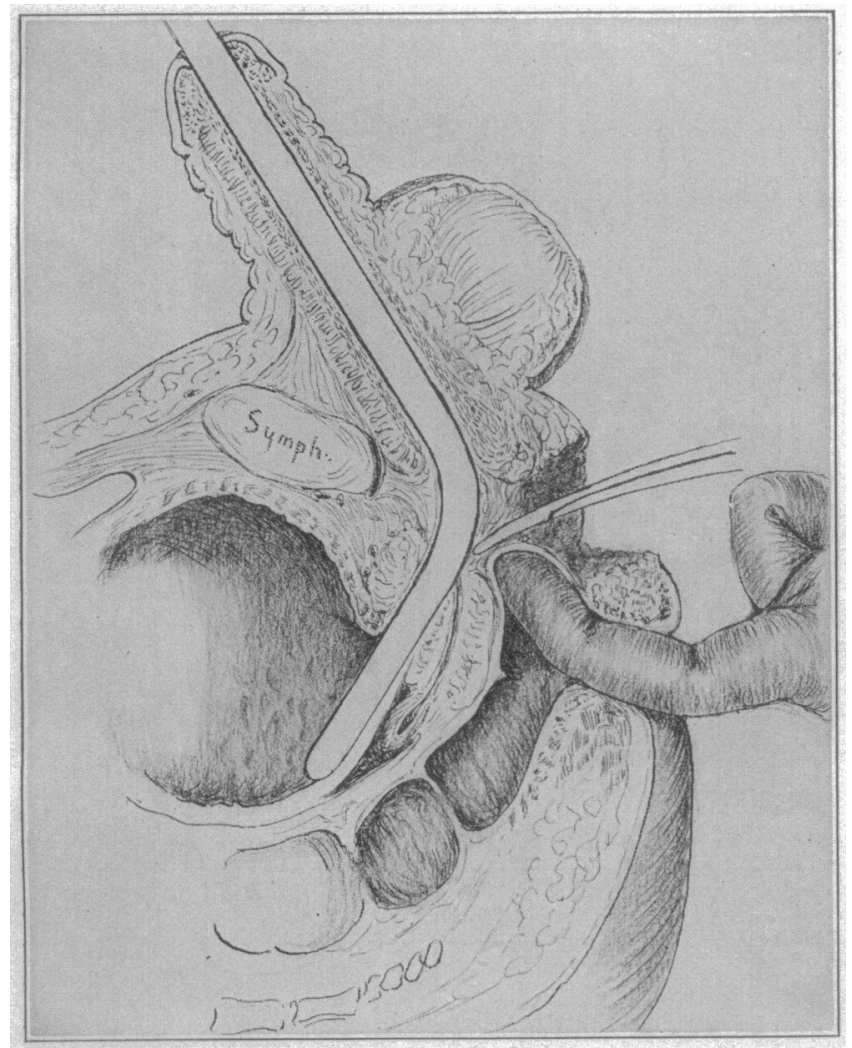

Fig. 5.-Sagittal section: finger in rectum guiding curved clamp as it is pushed down to the apex of the prostate.

\section{ABSTRACT OF DISCUSSION}

Dr. JAMES A. GARDNER, Buffalo: We have always had more or less friendly controversy between the advocates of the suprapubic and those of the perineal operation. In the perineal operation a slight incontinence is frequently found when men laugh or cough. When prostatics consult you they are ready to submit to any operation. When they return home after operation, if they have any incontinence, every one hears about it; but if they return home completely cured, nobody hears of it because, of course, that is what they came for. When I was doing the perineal operation I encountered the same complication, and for that reason I adopted the suprapubic method because it seemed more fool proof; there is no sinus and the patient has control. By this method the physician guards the rectum, and when he reaches the prostate he enucleates it just as is done from above. Dr. Cecil has gone a long way toward popularizing perineal prostatectomy. There is no question that more suprapubic operations are performed because many surgeons, seeing the operation, think it is not a difficult procedure. They try it, the patient lives and does not have incontinence, and soon they pose as genito-urinary surgeons.

Dr. Henry G. BugbeE, New York: One of the most important features, or the most important feature, to my mind, in the operation of prostatectomy is the control of hemorrhage. Various methods have been advanced from time to time to control the hemorrhage, particularly in the suprapubic operation. Hagner devised his bag, subsequently modified by Pilcher, and later on suggested putting a piece of cotton gauze over the bag to promote clotting. Barringer suggested packing the cavity. Recently $I$ have been packing around the bag, placing this packing carefully, particularly posteriorly to the bag so that it holds down the torn edge of the bladder wall, as that is where most of the bleeding takes place. By using this packing it is not necessary to put much traction on the bag, and this avoids the muscular spasm, which is often very troublesome. The bag and packing are removed twenty-four hours later through the suprapubic wound. Operating in two stages, at the second operation the stitches are not removed. The enucleation is carried out through the sinus with the finger and when the lobes are freed by holding them down in the capsule with the finger in the bladder, there is no difficulty in lifting them out. The sinus, which is very small, heals readily.

Dr. Arthur L. Chute, Boston: I should like to express my admiration for Dr. Cecil's operation. I am sure it will accomplish his desire. For a long time I have employed this principle in all my perineal operations. I do not use such attractive instruments as he does, nor do I think they are necessary. If one will be careful to make the incision through the tip of the prostate onto a sound placed in the urethra, he can easily introduce through the incision a straight tractor, pull the prostate down, and go ahead with the enucleation without the more elaborate apparatus that Dr. Cecil has found useful. It seems to me that by this technic not only does one avoid actual injury to the fibers of the sphincter, but one also avoids what I consider fully as frequent a cause of incontinence, and that is, the getting of the muscle fibers caught in the perineal scar. With the prostate exposed, one can use either a lateral or a transverse incision in the capsule. One can make use of a transverse incision, if one wishes. The posterior flap of the capsule acts as an extra protection to the rectum. I believe that the use of the suggestion that Dr. Cecil has made will insure us against injury of the sphincter and consequent faulty control of the urine, and if one adds to it a transverse incision in the prostatic capsule and turns the flap back, one will in a large measure avoid the possibility of injury to the rectum.

DR. A. RAYMOND STEVEns, New York: It is a great compliment to Dr. Young that so many years have gone by without any material modification of his operation being offered until this spring, when both Dr. Geraghty and $\mathrm{Dr}$. Cecil have come forward with new suggestions. They mark definite advances, and will tend to make the

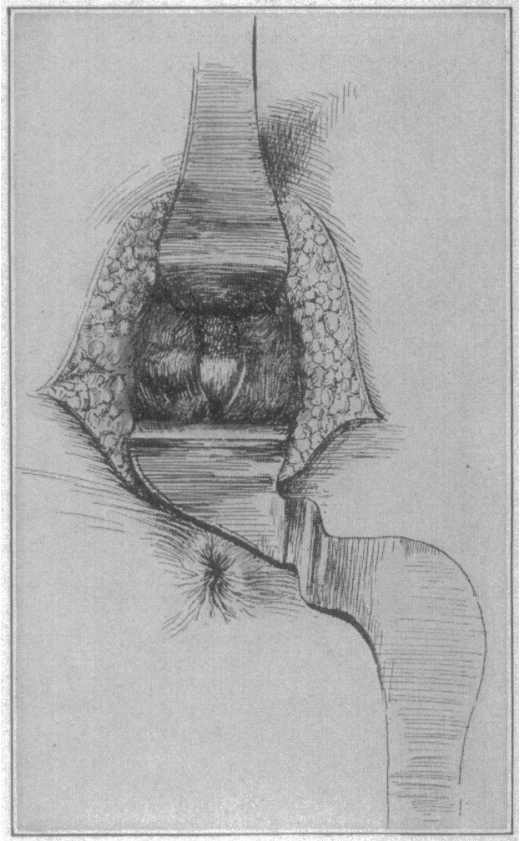

Fig. 6.-The tractor has been pushed into Fig. 6.- The tractor has been pushed into the bladder and opened. The tissues which and the prostate has been pulled up into the wound. cessful in the hands of the average operator. Dr. Chute took the words out of my mouth as to a means that I think many of us have employed in getting a little farther away from the external sphincter. I have been inclined to make my incision in the urethra farther and farther posterior, until recently I have been going right through the apex of the prostate. That also makes it very easy to palpate the vesical neck before closing the wound. Another point on which I think Dr. Cecil is to be congratulated is that he comes out 
very frankly and suggests that we protect the rectum by kecping one finger in this viscus when cutting the rectourethralis muscle. I have always felt that it was a matter of pride to cut through this muscle without this guide; but if no one is looking, I often put my finger in the rectum.

DR. A. I. Folsom, Dallas, Texas: The question Dr. Cecil brought up is very interesting. I have always felt that the perineal procedure has always been described very accurately up to the point Dr. Cecil is talking about, the external sphincter. In discussing the matter this morning, Dr. Cecil told me that Dr. Young has always pushed these fibers up with the back of the knife to get them out of the way. That has been hard for me to understand in any description of the operation, but I think Dr. Cecil's description will help many of us who have been chary about attacking the thing in this way. I think if we get enough of these perineal prostatectomists advocating modifications they must have a reason for them, and pretty soon we shall get the truth of every one's experiences in perineal prostatectomy. As these men have begun to do it themselves, they realize that perfection has not been reached, so I feel that there is an opportunity for good in the future if we go to the bottom of the situation and find out the truth. Regarding the question of

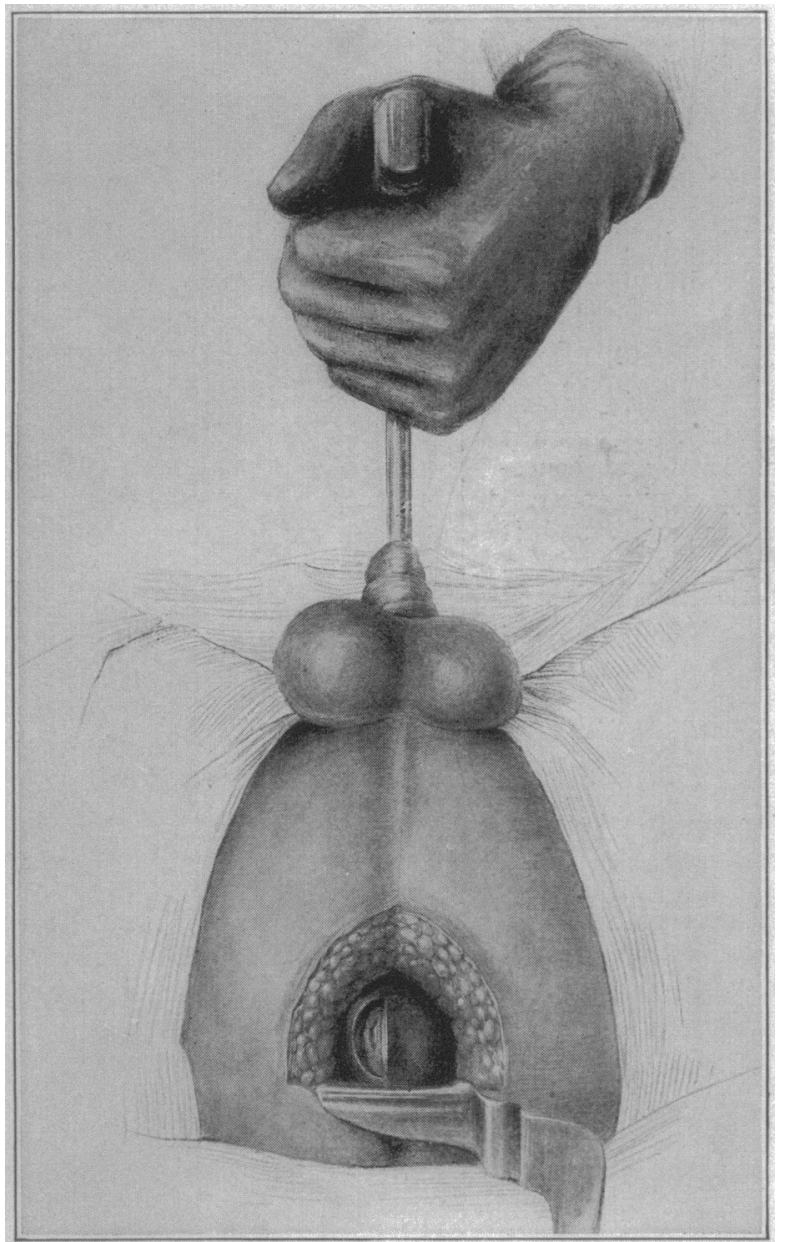

Fig. 7.-Prostate drawn into wound after rectum has been stripped back along the fascias of Denonvillier. A lateral incision has been made and the right lateral lobe has been removed. An opening has been nade into the prostatic urethra through this incision.

incontinence following prostatectomy, one cannot avoid the issue. Those patients are more or less incontinent for a certain length of time and there is no use to dodge the question at all. A few years ago it was stated that the external sphincter had nothing to do with this; it was proved by a beautiful series of roentgenograms that the internal sphincter was the all important sphincter, which I did not believe; and, as Dr. Cecil shows in his work, he himself believes that it is the external sphincter that really maintains the closed bladder.

Dr. John R. Caulk, St. Louis: Dr. Cecil is responsible for one of the great advances in this line. I do not believe it takes much courage, but I think he has done his duty nobly. I had one or two rectal complications, and the striking thing was that they always came when the case was simple and easy, so it is not the difficult cases that have the complications in all instances. They come when we do not

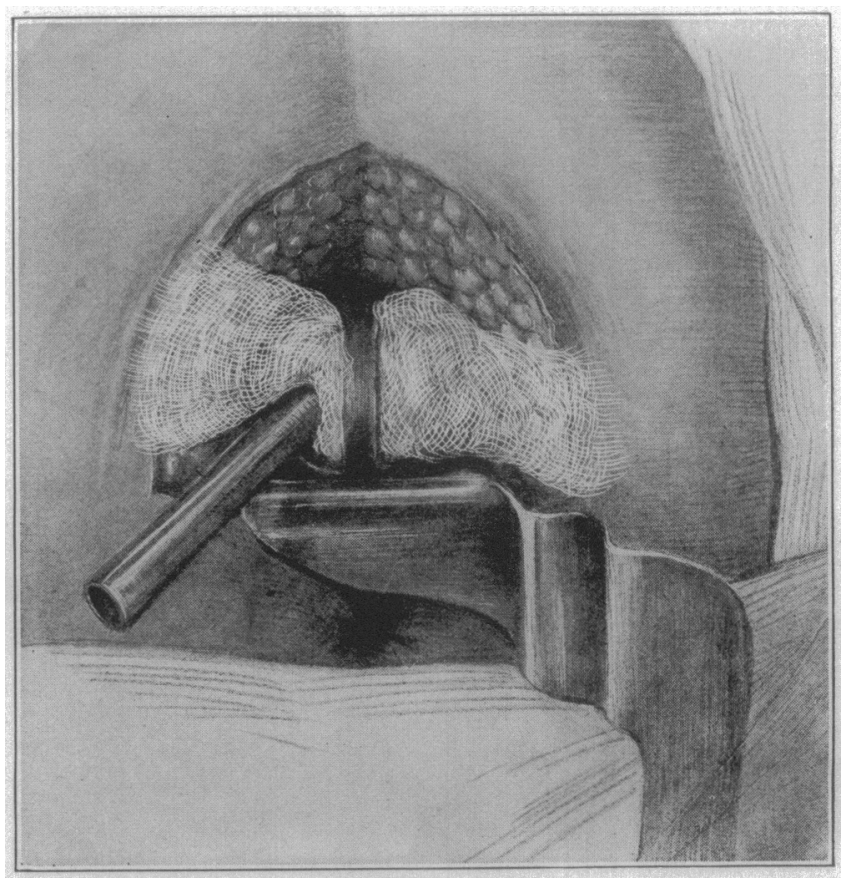

Fig. 8.-Prostatectomy completed: drainage tube introduced through right lateral cavity into bladder. Gauze packs have been introduced to control hemorrhages.

expect them. As to the incontinence, that occasionally occurs to all of us, although it is usually temporary. Because of the rectal complications I took up the two-stage operation, and have not regretted it. It is attended with a little more reaction to the patient, but he gets well and the final results are good. The fact that Dr. Cecil protects the sphincter and the rectum makes the operation simple, and I think it will avoid the complications which we used to have. If this is so, the perineal operation should be the one of choice in the hands of those familiar with it.

Dr. Arthur B. Cecil, Los Angeles: I have neglected giving credit to Dr. Chute for the idea on which I have based this procedure. Dr. Chute, in discussing perineal prostatectomy last year in Montreal, stated that it had been his principle to open the prostatic urethra far back, in fact, at the apex of the prostate, and in this way he had guarded the sphincter mechanism. To the average operator, however, it is not always easy to make this dissection accurately to the apex of the prostate, and that is the reason why I have devised the procedure which I have described, which has for its prime importance the preservation of the sphincter mechanism of the bladder, the absolute protection of the rectum, and a wider field of application than has heretofore been possible in perineal prostatectomy.

Infant Mortality and Nursing Service in Uruguay.-According to Dr. Julio A. Bauzá, director of infant milk stations in Montevideo, in 1920, over 2,000 infants under 2 years of age died out of a population of 363,000 inhabitants. The Public Health Department spends about one million pesos annually in infant homes, maternities and other infant welfare activities. The Red Cross of Uruguay has offered to furnish 100 visiting nurses for infant welfare work, the need of which has been very great. 